\title{
FORMAÇÃO DO ENFERMEIRO ACERCA DO GERENCIAMENTO: ENTRAVES E PERSPECTIVAS
}

\section{NURSING TRAINING ABOUT MANAGEMENT: OBSTACLES AND PERSPECTIVES}

\section{FORMACIÓN DEL ENFERMERO ACERCA DE LA GESTIÓN: OBSTÁCULOS Y PERSPECTIVAS}

\author{
Larissa Berghetti ${ }^{1}$, Laura Helena Gerber Franciscatto ${ }^{2}$, Caroline Ottobelli Getelina ${ }^{3}$
}

\section{RESUMO}

Objetivo: Compreender como os enfermeiros vivenciaram o gerenciamento após sua formação. Método: Pesquisa de cunho qualitativo descritivo e exploratório com abordagem fenomenológica, com doze enfermeiros. Os dados foram coletados, por meio de uma entrevista semiestruturada e analisados utilizando a análise temática proposta por Minayo. Resultados: Para uma melhor compreensão dos dados coletados (visam a responder aos objetivos da pesquisa por relatos dos enfermeiros acerca de suas vivências como gerentes após a formação), eles foram sistematizados em três categorias, sendo elas: Vivenciando o gerenciamento após a formação: principais problemas e desafios; Identificando a organização e as exigências do gerenciamento desenvolvido pelos enfermeiros em seus locais de trabalho; $O$ ensino do gerenciamento sob a óptica dos enfermeiros. Conclusão: Conclui-se que os sentimentos negativos no início de carreira do enfermeiro são inevitáveis, porém podem ser superados com perseverança, garra, determinação e busca por conhecimentos, de modo que, para a superação desses entraves, é fundamental a união entre os ensinamentos da instituição, a busca por saberes e as experiências adquiridas no dia a dia do enfermeiro para que, com isso, o profissional recém-egresso supere as angústias de seu começo de atuação.

Descritores: Organização e administração; Enfermeiros; Educação em enfermagem.

\section{ABSTRACT}

Objective: To understand how nurses experienced management after their training. Method: Descriptive and exploratory qualitative research with a phenomenological approach, with twelve nurses. We collected the data through a semi-structured interview and analyzed using the thematic analysis proposed by Minayo. Results: In order to better understand the collected data (aiming to respond to the research objectives using nurses' reports about their experiences as managers after their training), we systematized them into three categories. They are: living the management after they graduate: key problems and challenges; identifying the organization and management requirements developed by nurses in their workplaces; the management teaching from the nurses' perspective. Conclusion: We concluded that the negative feelings at the beginning of the nurses' career are inevitable, but they can be overcome with perseverance, determination, and search for knowledge. In order to overcome these obstacles it is essential to get together the institution teachings, the search for knowledge and the experiences acquired in the nurse's daily routine so that, with this, the newly graduated professional overcomes the anguish of its performance beginning.

Descriptors: Organization and administration; Nurses, male; Education, nursing.

\section{RESUMEN}

Objetivo: Comprender cómo los enfermeros vivenciaron la gestión después de su formación. Método: Investigación de cuño cualitativo descriptivo y exploratorio con enfoque fenomenológico, con doce enfermeros. Los datos fueron recolectados por medio de una entrevista semiestructurada y analizados a través del análisis de fases propuesto por Minayo. Resultados: Hay varios factores que dificultan la actuación del enfermero al inicio de la carrera, además de haber varias exigencias para conseguir poner en práctica la gestión. Y para que el recién egresado pueda superar estos desafíos y poner en práctica las herramientas necesarias para ejercer la gestión, es fundamental, la determinación y búsqueda de conocimientos. Las universidades, como instituciones formadoras, también deben contribuir para ello, deben propiciar vivencias prácticas y experiencias desde el inicio de la graduación. Conclusión: Se concluye que los sentimientos negativos, en el inicio de la carrera del enfermero, son inevitables, pero pueden ser superados por medio de la perseverancia, garra, determinación y búsqueda de conocimientos. Así, para la superación de estos obstáculos, es fundamental la unión entre las enseñanzas de la institución, la búsqueda por saberes y las experiencias adquiridas en el día a día del enfermero para que, con ello, el profesional recién egresado supere las angustias del comienzo de su actuación. Descriptores: Organización y administración; Enfermeros hombres; Educación en enfermería.

${ }^{1}$ Graduada em Enfermagem pela Universidade Regional Integrada do Alto Uruguai e das Missões. ${ }^{2}$ Graduada em Enfermagem. Doutora em Enfermagem pela Universidade Federal do Rio Grande. ${ }^{3}$ Graduada em Enfermagem. Doutora em Enfermagem pela Universidade Federal do Rio Grande. Docente na Universidade Regional Integrada do Alto Uruguai e das Missões.

Como citar este artigo:

Berghetti L, Franciscatto LHG, Getelina CO. Formação do Enfermeiro Acerca do Gerenciamento: Entraves e Perspectivas. Revista de Enfermagem do Centro Oeste Mineiro. 2019;9:e2820. [Access__]; Available in:__. DOI: http://dx.doi.org/10.19175/recom.v9i0.2820 


\section{INTRODUÇÃO}

O gerenciamento é imprescindível na prática diária do enfermeiro e a sua trajetória teve início com Florence Nightingale, pioneira dos cuidados em enfermagem, quando, na metade do século XIX, foi convidada para dirigir os hospitais militares de Scurati na guerra da Criméia. Para a reabilitação do cliente, Florence frisava a importância de sistematização e supervisão das atividades. Portanto, foi a partir da necessidade de se organizar os hospitais, que surge a importância do gerenciamento dentro da prática diária da enfermagem e, atualmente, a gerência não se restringe apenas à organização dos hospitais e sim a todo o cuidado designado ao cliente e, para isso, se faz imprescindível a realização da gerência da unidade e a gerência do cuidado, pois o objetivo da atuação do enfermeiro é a assistência qualificada e resolutiva ${ }^{(1-2)}$.

Para a execução do cuidado qualificado, é fundamental o gerenciamento da unidade e do cuidado de modo integral, tendo em vista uma assistência eficiente e de qualidade. Para que essa assistência seja efetiva, é preciso que o enfermeiro saiba organizar e coordenar as atividades e que torne possível a atuação da equipe de modo planejado e eficiente, buscando a resolutividade, satisfação do cliente e proporcionando, assim, motivação e reconhecimento da sua equipe ${ }^{(2-3)}$.

$\mathrm{Na}$ enfermagem, a gerência é necessária tanto no ambiente hospitalar quanto na saúde coletiva, exigindo dos profissionais competências variadas que permitam aos profissionais efetuar estratégias para solucionar os problemas encontrados na realidade vivida no momento pela instituição ${ }^{(1)}$.

Para que esses profissionais criem estratégias para solucionar os problemas, e sejam capazes de interceder de acordo com o que lhes é solicitado, tendo visão crítica e reflexiva, é fundamental que, durante a graduação, exista a integração entre a universidade e os serviços de saúde tanto do ambiente hospitalar como coletivo, para favorecer a reflexão dos alunos acerca do processo saúde/doença do paciente, família ou comunidade para que as ações de saúde desenvolvidas aos usuários sejam de acordo com sua realidade e necessidades.

A graduação em enfermagem apresenta disciplinas com atividades tanto teóricas como práticas, sendo essencial que os conteúdos e competências abordados no currículo proporcionem a capacidade do acadêmico e futuro profissional enfermeiro, a saber, executar suas atribuições, principalmente as de gerenciar e liderar, para assim alcançar a sublimidade em sua profissão.

A fim de que o enfermeiro consiga excelência no que lhe compete é preciso que ele seja líder motivado, criativo, inovador, visando ao cuidado ético e qualificado. Essas funções junto a competências da gerência como: planejar, tomar decisões, interagir são imprescindíveis para a sua atuação. Entretanto, nota-se uma falta de segurança, ansiedade do enfermeiro recémformado, pois o mesmo encontra-se em um período de transferência, em decorrência de sua saída da academia e entrada no mercado de trabalho. Esse período é considerado desafiador, em razão da vasta abrangência de responsabilidades que thes é incumbido. 0 profissional fica exposto a uma nova realidade, com um montante de demandas e competências ${ }^{(4)}$.

A preocupação com esse momento é algo comumente observado nos graduandos e egressos, em decorrência da exigência por enfermeiros qualificados, competentes e atualizados. Notam-se algumas dificuldades desses profissionais para assumir sua função de gerenciar, pois os mesmos apresentam restrições no que se refere a tomar decisões, e a se posicionar para a equipe, em razão da necessidade de aperfeiçoar suas habilidades referentes a algumas técnicas, procedimentos e condutas com a equipe e sua unidade de trabalho ${ }^{(5)}$.

Nesse contexto, surge o possível questionamento: Como os enfermeiros vivenciaram o gerenciamento do cuidado e dos serviços de saúde após a sua formação?

A literatura nos mostra que muitos enfermeiros, ao iniciar sua profissão, relatam encontrar diversos obstáculos, pois os mesmos chegam para o mercado de trabalho com ideias, saberes e visões construídas na graduação as quais, muitas vezes, são diferentes do que a rotina do local em que o novo profissional irá se inserir. $E$, quando esses novos profissionais querem colocar em prática todos os conhecimentos e vivências adquiridos na academia, encontram empecilhos que vão desde a insegurança em determinados procedimentos até a dificuldade de realizar com êxito suas competências que são: atenção à saúde, tomada de decisão, liderança, educação permanente, 
comunicação e gerenciamento. Essas situações, muitas vezes, causam angústia, ansiedade, pois as expectativas sobre o recém-graduado são inúmeras ${ }^{(3)}$.

Espera-se que o recém-egresso esteja preparado para assumir suas funções, e a universidade como instituição formadora, necessita capacitar os alunos para atuar na vida profissional. Nesta pesquisa, pretende-se auxiliar as universidades na preparação dos alunos em relação as suas competências, e possíveis desafios que poderão encontrar na vida profissional. Também visa a contribuir com o meio científico para que enfermeiros recémegressos tenham conhecimentos sobre os prováveis impasses encontrados no início de carreira, de modo que os influencie a buscar superá-los, por meio da procura por conhecimentos e experiências para conseguir executar com excelência a sua profissão e promover a satisfação da sua equipe e de seus clientes.

\section{MÉTODOS}

Estudo de cunho qualitativo descritivo e exploratório com abordagem fenomenológica. A pesquisa foi realizada em um município que está localizado na região Noroeste do Estado do Rio Grande do Sul, no período de 03 a 16 de julho. A seleção dos sujeitos ocorreu por meio da amostra por conveniência, na qual a participação dos sujeitos é voluntária, sendo que os indivíduos que possuíam menos de 6 anos de formação foram escolhidos, por seu interesse em contribuir com a pesquisa. Dos 55 enfermeiros atuantes no município, participaram do estudo 12 enfermeiros, sendo que 10 atuavam no hospital e 2 nas Estratégias de Saúde da família. Desses 12 indivíduos, quatro eram homens e oito mulheres.

A coleta de dados foi realizada no local de preferência dos participantes, por meio de entrevistas individuais semiestruturadas, de modo que o roteiro semiestruturado combina perguntas abertas e fechadas voltadas ao gerenciamento e início de carreira que foram realizadas de maneira informal, por meio de uma conversa, sendo que o tempo de duração das mesmas ocorreu entre oito e trinta minutos. As perguntas foram realizadas oralmente $e$ as respostas registradas com gravador, lembrando que o objetivo fora buscar dados e não discuti-los.

A avaliação dos dados foi realizada, por meio análise temática proposta por Minayo ${ }^{(6)} \mathrm{a}$ qual permitiu interpretar e descrever os dados obtidos nas entrevistas, por meio da identificação, análise e descrição, o que possibilitou organizar os dados colhidos e responder ao objetivo da pesquisa

Esta pesquisa envolveu seres humanos juntamente com outras informações e materiais e, em razão disso, foi assumido o cumprimento integral da resolução $466 / 12^{(7)}$ que rege as pesquisas com seres humanos.

$O$ projeto também foi qualificado por uma banca de professores, e após a aceitação foi encaminhado ao Comitê de ética em pesquisa da Universidade Regional do Alto Uruguai e das Missões - URI, campus de Frederico Westphalen para consentimento e aprovação dos responsáveis, sendo que o projeto obteve parecer favorável sob registro: CAAE 66597817.1.0000.5352.

Todos os participantes leram e assinaram o termo de consentimento livre e esclarecido.

A pesquisa garantiu a privacidade e o sigilo dos entrevistados e dos dados fornecidos pelos mesmos, bem como a liberdade de participarem ou desistirem da entrevista no momento em que desejassem. Para garantir a segurança do anonimato dos participantes, os dados foram manipulados somente pela pesquisadora.

\section{RESULTADOS E DISCUSSÃO}

Para uma melhor compreensão dos dados coletados, os quais visam a responder aos objetivos da pesquisa, por meio dos relatos dos enfermeiros acerca de suas vivências como gerentes após a formação, os dados foram sistematizados em três categorias, sendo elas:

\section{Categoria 1. Vivenciando o gerenciamento após a formação: principais problemas e desafios}

Concluir um curso de graduação é um momento único de grande realização e satisfação pessoal, onde o recém-egresso sente-se entusiasmado e vitorioso pela conquista da formação superior. É um momento ímpar de satisfação, porém esse momento também é marcado por angústia e ansiedade, pois o recémformado de enfermagem sabe da importância, seriedade, compromisso e responsabilidades que sua profissão exige. Em decorrência dessas exigências que a enfermagem abrange na atuação profissional do enfermeiro, o primeiro emprego é visto como um desafio que acompanha os recémgraduados em seus primeiros meses de atuação $^{(8)}$. 
Esse início de atuação é marcado por muita ansiedade e receios, pois encontram inúmeras dificuldades que se iniciam com o processo admissional e continuam com a sua adaptação ao serviço de saúde. Ao assumir a função de enfermeiro, o primeiro impasse que surge é a insegurança relacionada ao novo ambiente onde o recém-graduado precisa assumir a rotina, o controle do ambiente e de seus recursos para garantir uma assistência qualificada ${ }^{(8)}$. Abaixo, seguem as falas de dois enfermeiros, relatando como foi a vivência deles, ao ingressarem no primeiro emprego e a insegurança que sentiram ao responsabilizarem- se por suas atribuições como gerentes de uma unidade de serviço:

"[...]Eu acho que no começo você não sabe bem como é o setor, você não sabe como é que é o funcionário e ainda você tem aquela insegurança de que você acabou de se formar" (E09).

"Não entendia muito mesmo assim, não sabia por onde começar a gerenciar. Assim, logo que eu comecei a trabalhar, me sentia perdida[...]" (E10).

Nas falas relatadas acima é possível perceber a insegurança em assumir suas funções, principalmente as de gerenciar que exigem do enfermeiro a capacidade de saber planejar o trabalho, as demandas de serviços e os recursos disponíveis, sendo que, para que isso se torne possível é necessária à disposição adequada das tarefas e organização da equipe, onde 0 enfermeiro precisa saber coordenar o trabalho e delegar tarefas, funções aos colegas de serviço para que os objetivos de seu trabalho sejam executados com qualidade. Porém, isso é algo que deixa os recém-egressos receosos, pois os mesmos apresentam, muitas vezes, restrições no que se refere a tomar decisões e a se impor ${ }^{(5)}$. Abaixo, seguem falas de dois indivíduos entrevistados que mencionam medo em relação a tomar alguma decisão equivocada:

"Quando eu me formei, depois que eu comecei a trabalhar, o gerenciamento ele é muito complicado porque a gente fica ainda muito inseguro quando a gente faz as coisas né, então a gente tem esse medo de fazer alguma coisa errada, de você delegar alguma coisa errada pra alguém [...]" (E09).

"[...] isso era algo que eu tinha bastante dificuldade no começo de saber dar ordem, não é você saber mandar, é você saber delegar, você saber passar pra ele: olha você precisa fazer isso e isso" (E05).
Conforme mencionado acima pelos sujeitos entrevistados, o medo é um sentimento comum ao recém-egresso quando o mesmo assume suas funções. De acordo com a literatura, os profissionais apresentam receios em tomar atitudes erradas, delegando tarefas de maneira equivocada. A delegação de tarefas faz parte do trabalho, da atividade gerencial do enfermeiro, sendo essencial para um serviço produtivo, com envolvimento de toda a equipe. Quando o enfermeiro delega atividades ele multiplica seu tempo, dividindo com outros as suas atribuições. Entretanto, ao delegar uma tarefa, a responsabilidade sobre ela ainda pertence ao enfermeiro e, por isso, muitas vezes, o receio por parte do recém-egresso. Quando o enfermeiro delega tarefas de maneira adequada, é possível alcançar um cuidado qualificado, benéfico e também promover a interação entre sua equipe de trabalho ${ }^{(9-10)}$.

A relação entre a equipe também é algo fundamental para que o cuidado seja realizado de forma efetiva, porém, esse início de relacionamento, essa inserção com a equipe são desafiadores, é uma meta do recém-graduado em enfermagem a ser alcançada, quando o mesmo precisa se familiarizar e se inserir com a equipe, com a nova realidade. Essa inserção é considerada um entrave por parte dos recémgraduados. Abaixo, segue fala de um sujeito referindo-se a esse sentimento:

"Tu tem toda essa né, além do teu trabalho tu ainda tinha que fazer com que as pessoas te respeitassem, te aceitassem, então isso foi bem difícil porque as vezes tu chega pra trabalhar com uma pessoa que tem 25 anos de experiência na casa e aí tu é novo [...]" (E04).

De acordo com a fala anterior, os recémgraduados se sentem inseguros, com medo em relação à inserção e aceitação de sua equipe de trabalho. De acordo com a literatura, isso ocorre pela ansiedade dos recém-formados em conseguir executar suas tarefas da melhor maneira possível e também pela falta de preparação para enfrentar essa realidade, pois, muitos recém-formados não possuem o domínio e a segurança necessária para gerenciar a sua equipe, sendo que o gerenciamento da equipe é uma das atribuições que deve ser exercida pelo enfermeiro, e essa falta de preparo para gerenciar um grupo de trabalho deixa os enfermeiros recém-formados receosos, apreensivos $^{(11-12)}$ como relatado na fala do indivíduo abaixo: 
"A gente chega com medo, eu tinha muito medo. Além de dúvidas assistenciais, tinha muitas coisas que eram novas pra mim, tu sai da faculdade muitas vezes sem um preparo pra sair trabalhando e além de tudo isso gerenciar a tua equipe, é bem complicado" (E03).

Gerenciar a equipe de trabalho é laborioso para os profissionais recém-formados, pois os mesmos sentem-se inexperientes e, até mesmo, sem preparo para assumir essa atribuição, porém, de acordo com alguns autores, esses profissionais precisam buscar estratégias para exercer o gerenciamento de sua equipe, porque é de responsabilidade dos enfermeiros a coordenação dos colegas técnicos e auxiliares de enfermagem, de modo que devem conduzir esses indivíduos para que sejam capazes de exercer um processo cuidativo qualificado. Porém, as pesquisas trazem que a condução da equipe no início de carreira dos enfermeiros é marcada por cobranças e desconfianças por parte dos colegas com maior experiência, mais tempo de "casa"(13). Abaixo, segue fala de dois sujeitos entrevistados que comprovam a falta de confiança, a descrença da equipe com o recém-formado em enfermagem em seu começo de atuação:

"No início assim, primeiramente todo mundo sabe que você é recém-formado, já vem estampado em você, e os teus colegas que já estão trabalhando eles ficam te olhando com olhar diferenciado, entendeu, a enfermeira é recém-formada, vamos testar, vamos ver se ela sabe [...]" (E11).

"[...]Ah eles te testam, você tem que saber explicar pra ele o por quê que ele está fazendo aquilo porque ele as vezes pode até saber mas ele vai te testar pra ver se tu sabe" (E05).

Segundo as falas acima, ser aceito, acolhido pela equipe no início da carreira do enfermeiro é desafiador, pois existe resistência por parte dos colegas de trabalho, principalmente pelo fato de o recém-formado ser mais jovem e assumir um cargo de maior responsabilidade, como referido na fala abaixo do sujeito entrevistado:

"Você se forma, no meu caso, com 22 anos e o meu primeiro emprego foi com pessoas que já eram formadas há bem mais tempo, tinham até bem mais idade que eu, eu era a mais nova da unidade e entrei com a função de enfermeira, foi bem desafiador, porque desde as técnicas de enfermagem não era aquele aceitamento perante ter um enfermeiro" (E11).

De acordo com a fala acima e as duas anteriores o início da inserção, do aceitamento do enfermeiro por parte dos colegas não é fácil, pois o recém-graduado, geralmente, é jovem e inexperiente e isso causa resistência e desconfianças por parte da equipe, de modo que esses profissionais não confiam nos saberes e habilidades de seu gerente. A literatura informa que essa objeção, por parte dos companheiros de serviço, deixa os enfermeiros preocupados, com medo, pois ser acolhido e aceito pelos colegas é um passo importante para o bom funcionamento do serviço, bem como para a satisfação pessoal. E para que ocorra esse aceitamento por parte da equipe é fundamental que o enfermeiro como gerente busque demonstrar competência e conhecimentos tanto teóricos como práticos, para que com o decorrer do tempo e experiência construída a cada dia, esse profissional mostre que sabe, que é capaz, e assim construa sua história, sua imagem e almeje um espaço e o respeito na equipe e na instituição como gerente, líder de um grupo de trabalho ${ }^{(8)}$.

Gerenciar, liderar uma equipe de serviço exige muita responsabilidade, conhecimento, aprimoramento de encargos e avaliação de conceitos para que seu grupo trabalhe motivado, instruído a alcançar um cuidado qualificado. Essa assistência de qualidade se torna possível por parte da equipe quando o enfermeiro gerente sabe liderar. A liderança advém da administração e é uma das atribuições do enfermeiro que contribui para que o gerenciamento seja realizado de forma efetiva e satisfatória. Porém, liderar uma equipe, também é visto como dificuldade no início de carreira dos enfermeiros, pois eles preferem não apresentar segurança para exercer essa competência logo após a formação ${ }^{(5)}$. Abaixo segue relato de um sujeito entrevistado mencionando a insegurança em liderar logo ao iniciar a atuação profissional:

"[...] você é jovem, você tem aspecto de liderança, já vem embutido que você já se forma líder de equipe mesmo você não tem ainda capacidade técnica ainda você, pelo teu cargo você já é líder e isso é bem desafiador" (E11).

Conforme mencionado na fala acima, liderar é uma competência do enfermeiro que está completamente relacionado com o gerenciamento. sendo essencial na prática diária desse profissional, mas exercer essa atribuição é algo que deixa os recém-formados aflitos, pois é difícil, exige preparo e embasamento por parte da universidade e também busca de conhecimento pelo profissional. Para que o enfermeiro busque esses saberes, ele deve investir em aprendizados teóricos práticos e 
de pesquisa visando a aprimorar seus encargos, avaliar seus conceitos para que o cuidado seja resolutivo e para que o enfermeiro consiga liderar sua equipe. Além do que foi mencionado, para que o enfermeiro exerça uma boa liderança é fundamental que esse profissional proporcione um ambiente favorável para a execução das atividades de modo que deve buscar transmitir segurança a sua equipe fazendo com que todos atuem buscando o melhor resultado pessoal e profissional alcançando assim uma assistência de excelência ${ }^{(13)}$.

A assistência resolutiva e integral é o que se espera do enfermeiro recém-formado. Juntamente com esta capacidade aguarda-se desse profissional o conhecimento necessário para gerenciar sua equipe, sua unidade e o cuidado. Porém, estudos apontam que exercer o gerenciamento no início de carreira é um entrave, pois os profissionais durante a graduação recebem o embasamento teórico necessário e algumas vivências práticas, mas, às vezes, Ihes aparecem situações diferentes do esperado cabendo ao enfermeiro resolvê-las. E para que o enfermeiro solucione esses impasses, necessita de muitos saberes teóricos e conhecimentos adquiridos com a prática ${ }^{(11)}$. Abaixo, segue relato de indivíduo entrevistado referindo-se a essa necessidade:

"E a gente vai na verdade aprendendo o gerenciamento com o tempo, a gente chega e não tem muita noção de como vai ser tudo, desde escala de pessoal. A gente aprende tudo, mas quando vem pra pratica é que você começa realmente vivenciar isso" (E01).

Conforme relatado na fala acima, no início de atuação, o enfermeiro não apresenta saberes efetivos para gerenciar, porque, muitas vezes, não possui vivências práticas suficientes e também pela sua inexperiência. Essa insuficiência gera ansiedade no começo da atuação, e vai sendo superada com o tempo, por meio das experiências adquiridas, sendo elas assertivas ou não, pela busca da ajuda de profissionais mais experientes e, principalmente, pela procura de atualização, estratégias e conhecimentos por parte do enfermeiro. Quando o enfermeiro almeja investir em saberes, sua atuação gerencial é realizada de forma qualificada, ética, segura, resolutiva e diferenciada ${ }^{(14)}$.

Categoria 2. Identificando a organização e as exigências do gerenciamento desenvolvido pelos enfermeiros em seus locais de trabalho

A execução da competência de gerenciar por parte do enfermeiro é de extrema importância para que o cuidado seja qualificado e resolutivo, pois a gerencia em enfermagem visa a organizar o trabalho e os recursos humanos, com a finalidade de criar e implementar condições adequadas de serviço aos trabalhadores e de cuidado aos pacientes ${ }^{(15)}$.

A organização do trabalho é uma das funções básicas da gestão em todas as instituições, pois, por meio dela, é possível planejar e sistematizar os recursos humanos, tecnológicos e materiais assegurando assim uma assistência segura e de qualidade satisfazendo assim as necessidades dos pacientes assistidos ${ }^{(14-}$ ${ }^{15)}$. Estudos apontam que para que o cliente seja assistido de forma adequada e de acordo com as suas necessidades é imprescindível que o enfermeiro como gerente seja comprometido e responsável ${ }^{(16)}$, como afirmado na fala abaixo de um dos indivíduos entrevistados sobre a compreensão acerca das exigências necessárias para se colocar em prática o gerenciamento em seus ambientes de trabalho:

"Responsabilidade, comprometimento, assiduidade que eu acho bem importante, compromisso com o trabalho e com os usuários principalmente né, porque a gente trabalha na área do SUS né então as pessoas têm uma demanda e uma necessidade grande de atendimento e de atenção também né" (E12).

São inúmeras as exigências para que o trabalho gerencial do enfermeiro seja produtivo e eficiente. Exige-se que o enfermeiro gestor seja comprometido, criativo, motivado, ético, líder ágil, comunicativo dentre outras características que quando bem empregadas possibilitam qualidade de trabalho, harmonia e êxito em suas atividades. Além disso, esperam-se habilidades como percepção, comunicação e raciocínio rápido para que os profissionais sejam capazes de elaborar alternativas que contribuam para o crescimento da instituição ${ }^{(17-18)}$.

Para que o enfermeiro contribua para a expansão do seu local de trabalho e desempenhe suas atividades com excelência, além das exigências mencionadas acima é fundamental que o mesmo tenha conhecimento, pois, quando o enfermeiro tem domínio de suas habilidades, de seu ambiente, do perfil de seus clientes ele é capaz de perceber as necessidades dos indivíduos e resolvê-las. Ele também é capaz de lidar com imprevistos e executar tarefas esperadas pela sua profissão. Abaixo, seguem falas de três sujeitos que enfatizam a importância do conhecimento dentro da prática diária do enfermeiro gerente: 
"Ah, eu acho que é conhecimento teórico prático e tu ter conhecimento do ambiente em que tu está inserido, o paciente que tu tem, saber avaliar o técnico, o ambiente, o paciente, tudo" (E07).

"Tu pode ser a melhor pessoa pra passar sonda, mas se tu não tiver o conhecimento principalmente o teórico, se tu não tem esse conhecimento teórico desanda tudo e tu tem que ter humildade também de falar que não sabe, mas vamos procurar, vamos aprender juntos" (E04).

"As principais exigências, primeiro a gente precisa ter pulso firme senão a gente não vai conseguir impor o respeito que a gente precisa pros técnicos porque a gente precisa demonstrar primeiro que a gente sabe e que a gente tem confiança daquilo que a gente está fazendo né" (E09).

De acordo com as falas acima, percebe-se a importância do conhecimento, tanto teórico quanto prático, para que o enfermeiro desempenhe com excelência as suas atribuições, preste uma assistência qualificada e mostre-se seguro em relação as suas funções e responsabilidades. A sociedade atual está sempre se modificando, em decorrência das transformações que ocorrem nas áreas $d a$ comunicação, tecnologia e economia e essas mudanças exigem, cada vez mais, que os profissionais tenham conhecimentos, e busquem por atualizações visando a desempenhar suas respectivas funções, acompanhar e atender a demanda específica da profissão ${ }^{(19)}$.

A busca pelo conhecimento e atualização sustenta, cientificamente, a atuação gerencial do enfermeiro, sendo essencial para que esse profissional seja capaz de executar com êxito as suas incumbências e responder de forma concisa às exigências solicitadas pela profissão, pois, atualmente, destaca-se o enfermeiro gerente que é capaz de criar soluções inovadoras e eficientes para resolver os impasses do ambiente de trabalho, que possua visão ampla da instituição e das demandas de serviço ${ }^{(13-19)}$.

Diante das abordagens acima, é possível compreender que gerenciar é uma atribuição de extrema importância na atuação profissional do enfermeiro, pois, quando o enfermeiro realiza o gerenciamento, ele é capaz de desempenhar suas funções de forma eficiente, associando habilidades e saberes para resolver problemas, lidar com imprevistos e executar tarefas esperadas pela sua profissão.

\section{Categoria 3. 0 ensino do gerenciamento sob a óptica dos enfermeiros.}

Em nosso país, a formação do enfermeiro é fundamentada na Lei de Diretrizes e Bases da Educação Nacional no $9394 / 96^{(20)}$ que, objetiva formar profissionais generalistas, humanistas, críticos, capazes de atuar de forma ética e qualificada, de modo que sejam capazes de identificar e solucionar os problemas dos clientes com responsabilidade e compromisso, respeitando os valores e as normas da profissão(21).

Para que isso seja possível, é fundamental que, durante a graduação, os conteúdos curriculares abordem temas que possibilitem aos estudantes compreender 0 processo de saúde/doença dos indivíduos e as suas condições, permitindo aos graduandos prestar uma assistência focada na totalidade do indivíduo, utilizando seus recursos disponíveis. Uma das temáticas abordadas nos conteúdos curriculares que auxilia aos estudantes ter essa visão ampla do paciente, e também o conhecimento acerca de seus recursos é o gerenciamento ${ }^{(21-22)}$.

O ensino do gerenciamento é de extrema importância para a formação e atuação dos enfermeiros, pois ele permite ao profissional gerenciar a sua equipe, sua unidade $e$ a assistência designada ao cliente ${ }^{(22)}$.

O gerenciamento é considerado uma competência privativa do enfermeiro, em obediência à Lei $n=7.498^{(23)}$, sendo que o mesmo deve ser trabalhado ainda na graduação, para que as ações dos enfermeiros sejam embasadas cientificamente e também para que os profissionais tenham conhecimento de sua atribuição e estejam preparados para atuar profissionalmente. No entanto, de acordo com a fala dos sujeitos entrevistados, a graduação aborda a importância e as exigências incumbidas ao gerenciamento, porém, as universidades como instituições formadoras, deveriam cobrar mais dos alunos e também buscar formas que possibilitem uma melhor vivência e compreensão do graduando com a sociedade, ou seja, uma maior interação entre a teoria e a realidade dos pacientes, dos serviços ${ }^{(16)}$. Abaixo seguem falas dos indivíduos, relatando esse sentimento:

"Olha, algumas coisas sim sabe, mas o gerenciamento na graduação ele é muito teórico ali né, tu tem algumas formas de gestão que eles te ensinam, mas tu vim pra prática é bem diferente né. Lá a gente aprende o correto, mas, tem algumas coisas que aparecem na tua frente 
assim que você "putz" nunca pensei que ia acontecer comigo" (E03).

"Quanto mais realista a gente puder ter a visão na graduação é melhor porque depois a gente já tem uma ideia de como funciona né, não chega crua pra trabalhar" (E05).

Conforme relatado nas falas acima, a graduação possibilita aos graduandos uma visão da importância, seriedade e exigências necessárias para exercer o gerenciamento, porém os sujeitos entrevistados também se referem à necessidade de uma vivência prática maior para facilitar a compreensão acerca de suas responsabilidades e possíveis desafios, contribuindo assim para um melhor desempenho do gerenciamento e de uma visão crítica acerca de suas funções.

Para que os enfermeiros tenham uma melhor percepção crítica reflexiva e um melhor exercício de sua competência de gerenciar é necessário que as instituições formadoras busquem proporcionar uma maior vivência aos acadêmicos com a realidade dos pacientes e do ambiente de trabalho dos enfermeiros. Para isso, é preciso que a universidade procure a união com o serviço de saúde, tanto do ambiente hospitalar quanto do coletivo, objetivando, assim, favorecer a reflexão dos alunos acerca do processo saúde/doença do paciente, família ou comunidade para que as ações de saúde desenvolvidas aos usuários sejam de acordo com sua realidade e necessidades e também proporcionando assim aos graduandos experiências e conhecimentos que o auxiliarão em sua atuação como profissionais ${ }^{(24)}$. Abaixo, seguem falas de três indivíduos entrevistados, relatando a importância da união entre ensino e serviços para proporcionar vivências práticas, por meio de estágios:

"Eu acho que tinha que entrar mais em estágio né, nesse lado. Eu não me lembro de ter tido muita coisa nesse sentido na faculdade quando eu fiz, eu não me lembro de ter tido muito estágio de vivenciar com os enfermeiros das unidades básicas e dos hospitais o trabalho deles. Eu lembro que a gente ia e fazia a prática, a técnica, os procedimentos, mas eu não me lembro de ter visto muito o gerenciamento de um enfermeiro que tivesse trabalhando sabe num hospital" (E05).

"Eu acho que tinha que ter mais em estágio né, eu não lembro de ter tido muito estágio pro lado do gerenciamento [...] Então por isso que muitas vezes logo no começo tu apanha um pouco né, tem um pouco de dificuldade, justamente porque tu sai sem ter muita vivência. Acho que isso faria falta, tu ter mais estágio nessa área sabe. Pra tu saber como lidar, ter pelo menos uma noção e saber como lidar quando tu estiver trabalhando, porque fazer um procedimento se tu não sabe tu pede pra alguém, alguém te ajuda tu aprende, mas gerenciar é diferente" (E04).

Mediante os relatos acima, às instituições formadoras são essenciais para que os graduandos tenham vivências construtivas e benéficas que os auxiliarão em sua atuação profissional, por isso, a importância das mesmas proporcionarem essas inserções, mediante as realidades dos serviços e comunidades.

É fundamental que as universidades presem por uma formação generalista e também que busquem possibilitar experiências práticas e teóricas diversificadas, durante a graduação, proporcionando assim aos graduandos conhecimentos amplos e concisos. Porém, a busca pelo saber não é de responsabilidade apenas das universidades e sim também dos graduandos, de modo que cabe também a esses indivíduos a capacidade de buscar conhecimentos e de saber utilizá-los ${ }^{(22-24)}$. Abaixo, seguem falas de um sujeito que relata essa visão:

“[...] a graduação não vai te dar tudo, é você que tem que ir atrás, cada acadêmico tem que buscar a sua linha e tem que pesquisar, tem que buscar, vai fazer estágio, vai se informar, mas muita coisa a gente pode buscar mais eu acredito, até nos cobrar mais, eu acho que como acadêmico pode se cobrar mais sim" (E11).

Segundo a fala acima, é fundamental a busca do graduando pelo conhecimento, de modo que, quando se unem os ensinamentos da graduação com a procura por parte do aluno, a sua formação torna-se mais ampla de saberes, o que o auxiliará em sua atuação profissional, possibilitando ao indivíduo saber utilizar suas competências em benefício do gerenciamento de sua equipe, unidade e consequentemente da assistência ao paciente. Cabe às universidades dar subsídios aos graduandos, instigar os futuros profissionais para que tenham uma visão ampla e a capacidade de empregar suas competências da melhor maneira possível, porém, também cabe aos graduandos, durante a graduação e em seu desempenho como enfermeiros, buscar conhecimentos para estarem preparados a responder aos problemas e desafios que the serão impostos ${ }^{(16)}$. 
Mediante ao que foi abordado nessa categoria, percebe-se que é imprescindível a busca de saberes por parte do graduando e a procura por metodologias que ofereçam maiores vivências aos acadêmicos. Para isso, a formação universitária deve permitir uma visão crítica da profissão, mostrando a importância do papel social e político do enfermeiro na assistência, no gerenciamento, no ensino e na pesquisa, a fim de valorizar o profissional e alcançar melhores condições de trabalho e de formação ${ }^{(15-16,24)}$.

\section{CONCLUSÃO}

Nesta pesquisa, foi possível compreender que o gerenciamento é uma atividade essencial e predominante no trabalho dos enfermeiros, sendo então fundamental que os enfermeiros tenham conhecimento do significado e das responsabilidades que estão atreladas ao gerenciamento, para assim exercer sua profissão de forma eficaz e qualificada.

$O$ exercício da enfermagem com qualidade e eficiência é o objetivo dos enfermeiros recém-graduados, pois almejam realizar um trabalho de excelência, porém, esse início de carreira do enfermeiro é um período vivenciado por medos e incertezas, de modo que, neste estudo, foi identificado que, logo ao assumir a função de gerentes, os recém-egressos de enfermagem sentem-se inseguros para assumir as responsabilidades e demandas do serviço, de modo que esse começo de carreira profissional é marcado por fatores que dificultam e desafiam a atuação do enfermeiro logo após a formação, sendo que os entraves ao estrear a atribuição de gerentes identificados, nesta pesquisa, foram: medo ao tomar decisões, receio em posicionar-se para a equipe, angústia em delegar tarefas de maneira equivocada, preocupação em conseguir gerenciar a equipe, aflição em assumir a responsabilidade de líder, e apreensão em ser inserido, aceito por seus colegas de trabalho, principalmente pelo fato de apresentarem idade e experiência inferior aos outros profissionais atuantes, o que resulta em resistência e desconfiança dos demais indivíduos do grupo de trabalho.

Esses entraves que desafiam o início de carreira são comuns a todos os enfermeiros em seu primeiro emprego, em razão da inexperiência, e causam os mesmos sentimentos em todos eles, porém é algo que quando o recém-formado tem garra, determinação, vontade de fazer a diferença, e de seguir em frente pode ser superado, pelo dia a dia de trabalho, de novas vivências e experiências e também, por meio da busca pela atualização e saberes tanto teórico quanto práticos, o que, com o decorrer do tempo, fará com que o enfermeiro adquira destrezas e mostre que tem conhecimento e competência para exercer suas funções.

Além disto, este estudo possibilitou compreender que o exercício do gerenciamento exige organização dos recursos humanos, tecnológicos e materiais, assegurando, assim, um serviço de qualidade e o atendimento das necessidades dos clientes, de modo que as necessidades dos pacientes e da equipe sejam atendidas quando o enfermeiro organiza, planeja e utiliza ferramentas necessárias para colocar em prática o gerenciamento.

Esta pesquisa também identificou que o gerenciamento, sendo considerado uma competência privativa do enfermeiro, deve ser trabalhado ainda durante a graduação para uma melhor preparação do recém-graduado para exercer esta sua atribuição. Porém, de acordo com o relato dos sujeitos entrevistados, as universidades possibilitam aos estudantes de enfermagem uma visão das exigências precisas para executar o gerenciamento, mas os sujeitos entrevistados referem-se à falta e a necessidade de uma vivência prática, o que ajudaria os graduandos a ter uma compreensão maior acerca de suas responsabilidades e possíveis desafios, contribuindo assim para um melhor desempenho do gerenciamento e de uma visão crítica acerca de suas funções.

Para que os recém-graduados tenham uma melhor percepção crítica reflexiva e consigam desenvolver a competência gerenciar de forma satisfatória, é preciso que as universidades busquem proporcionar experiências e conhecimentos amplos e concisos, porém a responsabilidade pela busca e ampliação de saberes não é só de obrigação da universidade como também do recém-graduado, pois quando ocorre à combinação dos saberes advindos da universidade com a busca de saberes por parte do recém- formado, do enfermeiro, esse profissional torna-se mais preparado para responder aos problemas e desafios que the serão impostos, ou seja, é fundamental a conexão de conhecimentos, práticas e habilidades desenvolvidas, desde a graduação, formação e, de modo constante, na prática diária do enfermeiro. 
Salientamos, como limitação deste estudo, a sua realização em apenas um município, sendo então pequeno o número de profissionais com pouco tempo de formação. Portanto, destacamos a necessidade do desenvolvimento de outras pesquisas em outros cenários, pois sabe-se que as maiores dificuldades encontradas pelos enfermeiros são nos primeiros anos de formação.

\section{REFERÊNCIAS}

1. Rezende BC, Vasconcelos RMA, Lima SS, Santos OS, Aleixoi MLM. Dificuldades enfrentadas pelos enfermeiros na prática da liderança em enfermagem: Uma revisão da literatura. Gest Saúde 2013;4(2):2273-88. DOI: 10.18673/gs.v4 i2.22953

2. Santos HAS, Ferreira JOF, Leão JPS, David FS. A importância do gerenciamento de enfermagem na formação acadêmica: Relato de experiência. Rede Cuid Saúde 2016 [citado em 7 out 2018]; 10(3):1-3. Disponível em: http://publicacoes. unigranrio.br/index.php/rcs/article/view/3273/20 $\underline{32}$

3. Oliveira WA. Enfermagem: Desafios e dificuldades no início de carreira. REFACI 2017 [citado em 7 out 2018]; 2(2):1-19. Disponível em: http://revista.faciplac.edu.br/index.php/REFACl/a rticle/view/267/86

4. Jesus BH, Gomes C, Spillere LBB, Prado ML, Canever BP. Inserção no mercado de trabalho: Trajetória de egressos de um curso de graduação em enfermagem. Esc Anna Nery 2013 [citado em 7 out 2018]; 17(2):336-45. Disponível em: http:// www.revistaenfermagem.eean.edu.br/detalhe ar tigo.asp?id $=871$

5. Vilela PF, Souza AC. Liderança: Um desafio para o enfermeiro recém-formado. Rev Enferm UERJ 2010 [citado em 7 out 2018]; 18(4):591-7. Disponível em: http://www.facenf.uerj.br/v18n4/ v18n4a15.pdf

6. Minayo MCS. O desafio do conhecimento: Pesquisa qualitativa. 14a ed. São Paulo: Hucitec; 2014.

7. Ministério da Saúde. Resolução CNS/MS no 466, de 12 de dezembro de 2012. Diário Oficial da União 2012. Disponível em: http://bvsms.saude.gov.br/ bvs/saudelegis/cns/2013/res0466 1212 2012.h $\underline{\mathrm{tml}}$

8. Matossinho MMS, Coelho MS, Meirelles BHS, Souza SS, Argenta CE. Mundo do trabalho: Alguns aspectos vivenciados pelos profissionais recémformados em enfermagem. Acta Paul Enferm. 2010;23(4):466-71. DOI: 10.1590/S0103-21002010 $\underline{000400004}$
9. Dutra ES. Comunicação e relações humanas no trabalho de Enfermagem: Trabalho em equipe. Juiz de Fora: UFJF; [200-].

10. Sakamoto R. 14 atividades privativas do enfermeiro. Enfermeiro Aprendiz [citado em 7 out 2018]; 2016. Disponível em: http://www. enfermeiroaprendiz.com.br/14-atividadesprivativas-do-enfermeiro-entenda-tambem-asatribuicoes-dos-auxiliares-e-tecnicos-deenfermagem-neste-contexto

11.Souza LPS, Silva WSS, Mota EC, Santana JMS, Santos LGS, Silva CSO, et al. Os desafios do recém-graduado em enfermagem no mundo do trabalho. Rev Cuba Enferm. 2014 [citado em 7 out 2018]; 30(1):4-18. Disponível em: http://www. revenfermeria.sld.cu/index.php/enf/article/view/ $\underline{127 / 79}$

12.Martins A., Cardoso ML. Uma reflexão crítica sobre as dificuldades do enfermeiro recémformado no exercício da liderança. Vitrine Prod Acad. 2015 [citado em 7 out 2018]; 3(2):144-52. Disponível em:

file:///C:/Users/user/Downloads/41-42-1PB\%20(2).pdf

13.Silva VLS. Práticas de liderança em enfermagem executadas por enfermeiros em organizações hospitalares [dissertação]. Ribeirão Preto (SP): Universidade de São Paulo; 2015.

14. Sade PMC, Peres AM, Wolf DG. A formação das competências gerenciais do enfermeiro: Revisão integrativa. Rev Enferm UFPE. 2014;8(6):1739-45. DOI: 10.5205/reuol.5876-506 10-1-SM.0806201438

15.Lorenzetti J, Oro J, Matos E, Gelbcke FL. Organização do trabalho da enfermagem hospitalar: Abordagens na literatura. Texto Contexto-Enferm. 23(4):1104-12. DOI: 10.1590/ 0104-07072014001510012

16. Nascimento SM. As funções gerenciais do enfermeiro no cotidiano da assistência hospitalar [dissertação]. Rio de Janeiro (RJ): Universidade Federal do Estado do Rio de Janeiro; 2013.

17.Ferst EH. A qualificação do enfermeiro enquanto gestor [monografia]. Porto Alegre (RS): Universidade Federal do Rio Grande do Sul; 2015. 18. Rossés GF. Introdução à administração. Santa Maria, RS: UFSM; 2014.

19.Valduga T. Competências fundamentais do enfermeiro gestor. Setor Saúde [citado em 7 out 2018]; 2013. Disponível em: https://setorsaude. com.br/teresinhavalduga/2013/01/15/competen cias-fundamentais-do-enfermeiro-gestor

20.Brasil. Casa Civil. Lei no 9.394, de 20 de dezembro de 1996. Estabelece as diretrizes e 
bases da educação nacional. Diário Oficial da União 1996. Disponível em: https://proplan. ufersa.edu.br/wp-content/ uploads/sites/7/2014/ 09/LEI-n\%C2\%B0-9.394-de-20-de-dezembro-de1996.pdf

21. Brasil. Ministério da Educação. Parecer CNE/CES 1.133/2001, de 7 de agosto de 2001. Diretrizes curriculares nacionais dos cursos de graduação em enfermagem, medicina e nutrição. Brasília: MEC; 2001.

22.Tonhoma SFR, Moraes MAA, Pinheiro OS. Formação de enfermeiros centrada na prática profissional: Percepção de estudantes e professores. Rev Gaúcha Enferm. 2016;37(4):1-9. DOI: $10.1590 / 1983-1447.2016 .04 .63782$

23. Conselho Federal de Enfermagem (COFEN). Lei no 7.498 , de 25 de junho de 1986 . Dispõe sobre a regulamentação do exercício da Enfermagem e dá outras providências. Diário Oficial da União 1986;1:9273-9275.

24. Ortega MCB, Cecagno D, Llor AMS, Siqueira $\mathrm{HCH}$, Montesinos MJL, Soler LM. Formação acadêmica do profissional de enfermagem e sua adequação às atividades de trabalho. Rev Latino-Am Enfermagem 2015;23(3):404-10. DOI: 10.1590/ $\underline{0104-1169.0432 .2569}$

Nota: Este estudo faz parte da monografia de fim de curso intitulada "A formação do enfermeiro acerca do gerenciamento: Entraves e perspectivas", para a obtenção do título de Bacharel em enfermagem pela Universidade Regional Integrada do Alto Uruguai e das Missões (URI), Campus de Frederico Westphalen.

Recebido em: 12/03/2018

Aprovado em: 08/11/2018

Endereço de correspondência:

Larissa Berghetti

Rua Julio de Castilhos, 87- Ipiranga

CEP: 98500-000 - Tenente Portela/RS - Brasil

E-mail: larissaberghetti@hotmail.com 